\title{
Anteproyecto de la Revista de Arte y Ambiente El Tentáculo
}

\author{
Adolfo Córdova Ortiz* \\ Director de tesis: Dr. Ignacio Padilla Suárez. \\ UnIVERSIDAd DE las AMÉrICAS Puebla
}

La propuesta de esta revista está concebida principalmente desde la perspectiva de los denominados "medios no convencionales", y pretende ofrecer una visión integradora del arte y el medio ambiente apelando a la toma de conciencia, a la conservación y al escape lúdico y gozoso.

La investigación se divide en dos partes. En la primera, se delinea un panorama general de las formas de producción mediática dominantes y su contraparte. A partir de un análisis de las características de las industrias culturales, sopesado con enfoques más contemporáneos, se abordan los motivos por los cuales los medios no convencionales están cobrando fuerza, y constituyéndose como una opción más libre, inclusiva, respetuosa y profesional de emitir mensajes. También se incluyen los riesgos de la contracultura, materia prima de algunos medios no convencionales, para evidenciar las fallas en las que pueden incurrir este tipo de medios, y denotar la importancia de fomentar la autocrítica al interior de éstos.

En la segunda parte, se ofrece un panorama editorial de revistas culturales y ambientales en México, se analiza el rol de internet frente a la

\footnotetext{
* Adolfo Córdova es un periodista ambiental coeditor y fundador de la revista ambiental Verde, del periódico Reforma, y colaborador para otros suplementos especiales y revistas de ese medio. Se licenció con honores de la carrera en ciencias de la comunicación de la Universidad de las Américas Puebla. Ha recibido becas para participar y cubrir congresos ambientales al interior de México y en países como Canadá, Estados Unidos, Puerto Rico, Argentina, Bélgica, Corea del Sur e Indonesia.
} 
gráfica impresa, se recogen diversas opiniones sobre la lectura en México y se puntualiza por qué la prensa, en particular las revistas, tienen mucha afinidad con los medios no convencionales, y pueden ser una vía idónea para constituir una publicación como la que propongo.

\section{Medios no CONVEncionales (PRIMERA PARTE DE LA TESIS)}

Resulta fundamental, cuando se habla de industrias culturales, considerar que la reproductibilidad técnica también permitió una primera democratización en el acceso a los medios. La industria cultural, como el mercado en general, tiene muchas fallas, pero eso no quiere decir que sea deficiente. Hizo falta sí, que se desmenuzaran sus efectos para evidenciar la falta de un equilibrio en los flujos informativos, y proponer alternativas, pero la cultura de masas y la producción en serie tiene un sitio porque es igualmente necesaria.

Es cierto que los públicos no son una masa indiferenciada, y que aunque en general no muestren derroches de participación, sí existen manifestaciones de organización y acción a partir de las discusiones que animan los medios, pero igualmente es válido observar que la proliferación de estilos de vida homogéneos, subrayados también por los medios, conllevan a desigualdades sociales y desgastes ambientales.

El intercambio informativo poco balanceado, la producción de contenidos repetitivos, la exclusión de temáticas "incómodas", los filtros en la generación de mensajes, son algunos de los vicios que se pueden abordar de los medios convencionales. Muchos son los matices en medio pero no se puede negar que desarrollar una contraparte a estos modos de operación es obligatorio.

Hay que resaltar las enormes posibilidades de los medios no convencionales para diversificar las formas, atender las necesidades expresivas de una comunidad, reafirmar identidades, devolver la voz y la visibilidad a las temáticas tantas veces negadas, ignoradas o tomadas como triviales. Pero también hay que tomar en cuenta que la noción de medios no convencionales es tan amplia que no deberían emitirse juicios deterministas al respecto. Los medios no convencionales no son completamente ajenos a los mismos mecanismos de difusión que utilizan los medios convencionales, y viceversa. Finalmente ambas posturas mediáticas representan la voz de un interés. Los medios no convencionales también forman parte de una industria. Lo que sucede es que el interés del medio convencional corresponde más con la línea de pensamiento aceptada, acordada y adoptada según los intereses económicos y políticos de un orden del mundo más o menos dominante. Y 
el medio no convencional, difunde información que cuestiona ese orden, o no, y que simplemente da a conocer identidades y expresiones del ser humano que no figuran en los medios, sin que necesariamente haga algún tipo de denuncia política.

Por otra parte, cuando los medios no convencionales cuestionan ese "orden", como vimos con la crítica a la contracultura, pueden caer en muchos vicios y en lugar de generar cambios sociales reales, sólo aparentan ser "alternativos", sin generar ni proponer soluciones viables. De ahí que haya que contener el descrédito general que hacen muchos abanderados no convencionales de los medios convencionales, y enfrentar el entusiasmo con el que defienden la alternatividad, muchas veces más empírico que teórico, con los vicios en los que también pueden incidir.

El problema se da cuando la contracultura se apodera del medio, con una cerrazón ideológica que impide el diálogo, la autocrítica, el análisis, y la inclusión. La mayoría de los teóricos no convencionales que analicé sí guardan sus reservas diciendo que el terreno todavía es muy amplio, pero tampoco aventuran mucho en las implicaciones totales que pueden derivar de sus movimientos.

Para los rebeldes contraculturales la culpa de todo la tiene "el sistema", y por eso hay que erradicarlo. Afirmar esto no sólo es peligroso, también es fácil. Una articulación de voluntades y denuncias se puede hacer dentro del sistema que conocemos, no al margen. Nuestros sistemas económico y político tiene muchas fallas y en la medida en que abordemos las problemáticas con seriedad y voluntad de diálogo, se podrán encontrar los mecanismos para mejorarlos.

Debo apuntar que entre convencional y no convencional hay muchos híbridos. Existen casos de medios con formas de operar "no convencionales" e intenciones que apuntan a convenciones extremas (nazismo, evangelismo), y otros que con una estructura convencional introducen temáticas poco difundidas.

La importancia de no encasillarse en una definición de los medios y una postura ideológica, tiene que ver con la capacidad de desarrollar productos verdaderamente auténticos, congruentes, innovadores, creativos y persuasivos.

Porque más allá de cualidades y debilidades de los medios, lo primordial es enfocarse en los proyectos, en el tipo de contenidos que se quieren ofrecer, repensar las formas y plantearse retos creativos. 
La prensa de revistas resulta idónea para explorar y desarrollar las características de los medios no convencionales, ya que por ser una forma del periodismo, cumple una función, al menos idealmente, de vigilancia del gobierno y de otras tantas formas de autoridad. Una buena parte de los medios no convencionales también cumplen esta función. Combinar lo que en términos éticos y profesionales se espera del periodismo, con otros principios no convencionales, como la independencia y la autogestión, puede dar como resultado proyectos integrales de comunicación que sean un verdadero referente informativo para la sociedad. Además pueden constituir espacios para el debate y la participación, distintos de los formatos donde el público es un espectador pasivo que mira con aceptación las posturas de periodistas de renombre y ve limitada su exposición a expresiones culturales más diversas.

En una época donde partidos políticos y empresas discuten en privado lo que debería ser un debate público; y donde televisoras y diarios nacionales forman parte de corporativos transnacionales más preocupados por expandir sus dominios económicos y favorecer a quienes faciliten esta expansión, que en ofrecer enfoques críticos de la realidad y caminos posibles de la democracia; recuperar la responsabilidad social de la prensa resulta una tarea que los medios no convencionales deben enfrentar. Lo están haciendo.

El panorama editorial y cultural en México no es tan desolador como se cree. Sí existen opciones, sí hay productos mediáticos intermedios y agrupaciones que arman sitios en internet, boletines y revistas para exponer puntos de vista más diversos y más críticos. Es necesario conocer el mercado editorial, informarse de la producción de libros y revistas y de los hábitos de consumo cultural, para evitar reducir las opiniones y las posibilidades de esta industria al típico “en México no se lee". Esa postura es una salida fácil ante el reto de conocer a los públicos, segmentarlos y generar productos editoriales más creativos.

En la actualidad, que el internet supone una fuente de distracción e información cada vez más popular, mostrar los valores agregados que da la experiencia física de la lectura de revistas y libros, puede ser una de las opciones para generar más lectores, aunque al final se trate más de colaborar e integrar las distintas plataformas para conseguir objetivos comunes, que de competir entre sí por las audiencias.

El horizonte de revistas de arte y cultura es amplio y las formas de operar también. No es tan variada, sin embargo, la oferta de revistas ambientalistas, lo que constituye un punto a mi favor en un contexto que 
se dice cada vez más sensible de las problemáticas ambientales pero que avanza lento en la implementación de las medidas necesarias para revertirlas. Este auge de la temática ambiental y esa escasez de revistas que atiendan el tema, podrían favorecer las posibilidades de encontrar apoyos y patrocinios para El Tentáculo.

Además, no encontré registros de revistas que vinculen lo ambiental con lo artístico. La convergencia entre arte y ambiente quiere decir que no estamos separados de la naturaleza ni del arte, que a todos nos toca y nos afectan estas áreas. Estoy seguro que una revista así tiene un lugar. Acercar al público al arte y a la naturaleza y mostrar los puntos de coincidencia para generar una reflexión o un goce a partir de la creación, la imaginación, el consumo responsable, el cuerpo, la literatura, el paisaje, la justicia, la danza, el olvido, el deseo, la belleza, la espera, la paciencia, el viaje, el humor, el juego.

Conseguir articular un punto medio para la base ideológica de la revista fue necesario para la propia concepción de esta tesis. La revista que planteo no es el lugar común de los medios no convencionales, pero su ánimo sí está comprendido por los teóricos de estos medios. No se trata de ser perseguidores políticos, pero sí constituir un espacio para vincular y dar voz a proyectos sociales, ambientales, artísticos, y para escaparse, para distraerse, para gozar del arte en su versión más lúdica.

El Tentáculo quiere explorar sus capacidades intertextuales. Pretende ampliar la concepción que se tiene de las revistas, para mostrar que existen más allá del papel impreso y de las letras, y tomar otras formas y otros caminos. Que los lectores lleven la oferta de El Tentáculo a otros planos, que cambie su manera de entender y vivir su realidad más cercana. Hacer evidente lo que se puede contar, narrar, y por supuesto leer, en diferentes formas, explorar en los géneros periodísticos y literarios, y desde diferentes lugares, variar los tonos y las posturas. Que la revista como medio de comunicación transmita contenidos alternos, producto de una colaboración interdisciplinaria. El Tentáculo quiere tocar al lector con ideas que le revelen mundos distintos, que lo coloquen en otra realidad, y generen un punto de encuentro más allá de la publicación.

\section{RECOMENDACIONES GENERALES}

1. Asumir posiciones ideológicas intermedias. Ponderar aciertos y debilidades de las experiencias no convencionales para evitar caer en el negocio de la contracultura. No es que los argumentos de la contracultura carezcan de relevancia, el problema es la cerrazón con la que los tratan sus defensores. 
2. Fomentar la elaboración de textos críticos.

3. Fomentar una toma de conciencia, una introspección y autocrítica al interior de los medios no convencionales y de los movimientos sociales.

4. Voluntad para investigar cuál es la mejor manera de lograr que nuestro producto informativo llegue a su público, lo involucre y constituya una verdadera alternativa en el panorama editorial.

5. Atender el auge de internet desarrollando vinculaciones entre el producto impreso y las ventajas multimedia en la red.

6. Diseñar opciones entretenidas, lúdicas, serias y educativas para animar la lectura.

7. Creer en el camino independiente. La autogestión puede ser la clave para el desarrollo congruente y exitoso de un proyecto personal o grupal.

8. Conformar redes para el intercambio de experiencias editoriales con otras revistas.

Ahora que miro hacia atrás el camino recorrido para la realización de esta tesis, me cae el peso de las doscientas ochenta y tantas hojas y una sensación urgente por liberarme de ellas, dejarlas reposar e imaginar el reencuentro más adelante. Un reencuentro que espero no sea individual y que le dé sentido a estas páginas más allá del que tiene como requisito académico. Que la tesis sea el referente desde el cual siga actualizándome, cuestionándome y encontrando la manera de cristalizar el proyecto. El reto del lanzamiento es grande pero también mi voluntad.

Decía Chopin que la certidumbre es engañosa, y que sólo vacilar es duradero. No sé qué siga exactamente después de este ciclo y de esta investigación. El Tentáculo apenas puede aferrarse a una idea, y aunque queden dudas, es un punto de partida: El primer paso en un viaje de mil millas. 